\title{
(2) OPEN ACCESS \\ Modelling the impact of menthol sales restrictions and retailer density reduction policies: insights from tobacco town Minnesota
}

\author{
Todd B Combs (D) ,' Virginia R McKay, ${ }^{1}$ Joseph Ornstein, ${ }^{2}$ Margaret Mahoney, ${ }^{3}$ \\ Kerry Cork, ${ }^{4}$ Deena Brosi, ${ }^{5}$ Matt Kasman, ${ }^{6}$ Benjamin Heuberger, ${ }^{6}$ Ross A Hammond, ${ }^{2,6}$ \\ Douglas Luke ${ }^{2}$
}

\begin{abstract}
${ }^{1}$ Center for Public Health Systems Science, Washington University in St Louis, St Louis, Missouri, USA

${ }^{2}$ Brown School, Washington University in St Louis, St Louis, Missouri, USA

${ }^{3}$ Minneapolis, Minnesota, USA

${ }^{4}$ Public Health Law Center,

Mitchell Hamline School of Law,

Saint Paul, Minnesota, USA

${ }^{5}$ Colorado School of Public

Health, University of Colorado at Denver-Anschutz Medical

Campus, Aurora, Colorado, USA

${ }^{6}$ Center on Social Dynamics and

Policy, Brookings Institution,

Washington, DC, USA
\end{abstract}

\section{Correspondence to}

Dr Todd B Combs, Center for

Public Health Systems Science,

Washington University in St.

Louis, St. Louis, Missouri, USA;

toddcombs@wustl.edu

Received 1 February 2019

Revised 14 June 2019

Accepted 19 July 2019

Published Online First

28 August 2019

\begin{abstract}
Introduction Tobacco control policies focused on the retail environment have the potential to reduce tobacco use and tobacco-related health disparities through increasing direct and indirect costs. Recently, national and subnational governments have begun to restrict the sale of menthol products and reduce tobacco retailer density.

Methods We developed an agent-based model to project the impact of menthol cigarette sales restrictions and retailer density reduction policies for six types of communities and three priority populations. During each simulated day, agents smoke cigarettes, travel in the community and make purchase decisions - whether, where and which product type to purchase-based on a combination of their own properties and the current retail environment.
\end{abstract}

Results of the policies tested, restricting all cigarette sales or menthol cigarette sales to tobacco specialty shops may have the largest effect on the total (direct and indirect) costs of purchasing cigarettes. Coupling one of these policies with one that establishes a minimum distance between tobacco retailers may enhance the impact. Combining these policies could also make the costs of acquiring cigarettes more equal across communities and populations.

Discussion Our simulations revealed the importance of context, for example, lower income communities in urban areas begin with higher retailer density and may need stronger policies to show impact, as well as the need to focus on differential effects for priority populations, for example, combinations of policies may equalise the average distance travelled to purchase. Adapting and combining policies could enhance the sustainability of policy effects and reduce tobacco use.

\section{INTRODUCTION}

Traditional tobacco control policies (e.g., smokefree policies, tobacco product taxes) are strategies that have a broad impact in reducing tobacco use and exposure among the general population. The US Surgeon General found in 2014 that greater restrictions on the sale of tobacco products could accelerate the elimination of tobacco use. ${ }^{1}$ Tobacco control policies focused on the retail environment also have the potential to reduce tobacco-related health disparities. ${ }^{2}$ As a result, targeting the tobacco retail environment, including restricting the sale of menthol products and reducing tobacco retailer density, is rapidly emerging as the next frontier in tobacco control policy.

In 2016, WHO issued an advisory note unequivocally recommending a ban on 'the use of menthol and its analogues, precursors or derivatives in cigarettes and possibly all tobacco products'. ${ }^{3}$ In recent years, several countries have implemented menthol tobacco restrictions: the European Union passed a Tobacco Products Directive that includes a ban on menthol cigarettes and roll-your-own tobacco by 20 May $2020,{ }^{4}$ and in 2017, Canada passed a law prohibiting the manufacture and sale of all menthol cigarettes, blunt wraps and most cigars. ${ }^{5-7}$ Other countries, including Brazil, Ethiopia, Turkey, Uganda and Moldova, have also passed regulations to prohibit the sale of menthol cigarettes and other flavoured tobacco products. ${ }^{8}$ Over the past several years, both the US Food and Drug Administration and an independent scientific advisory committee have reviewed a wealth of scientific evidence on the health effects of menthol ${ }^{910}$ and found that the removal of menthol cigarettes would have a positive impact on public health. In the absence of US federal action to regulate menthol tobacco products, a growing number of cities and counties are implementing policies restricting sales of flavoured tobacco products; many include menthol products. ${ }^{11} 12$

The recent focus on retail regulation also includes measures to reduce the number of tobacco retail outlets in communities, since higher retailer density is associated with greater tobacco use among youth and decreased quit attempts for adults. ${ }^{1}$ While retailer density reduction policies are being passed internationally, little is known about the underlying mechanisms or eventual outcomes. One study reports that Turkey, China, Ghana and most Canadian Provinces prohibit sales in pharmacies, ${ }^{13}$ and countries, such as Scotland, are actively researching the effectiveness of more comprehensive retailer density reduction policies. ${ }^{14}$ States and local governments throughout the USA are passing policies to reduce or restrict the number and location of stores allowed to sell tobacco and, accordingly, the density of tobacco retailers. ${ }^{111516}$ Minneapolis is one city that recently implemented a menthol restriction, and many other communities in Minnesota have implemented retailer density restrictions or policies affecting menthol product sales (see 'Spotlight on recent policy’ at https://tobaccotown.shinyapps.io/ Minnesota/ for more details). Here, we estimate the potential impact of these types of policies. 


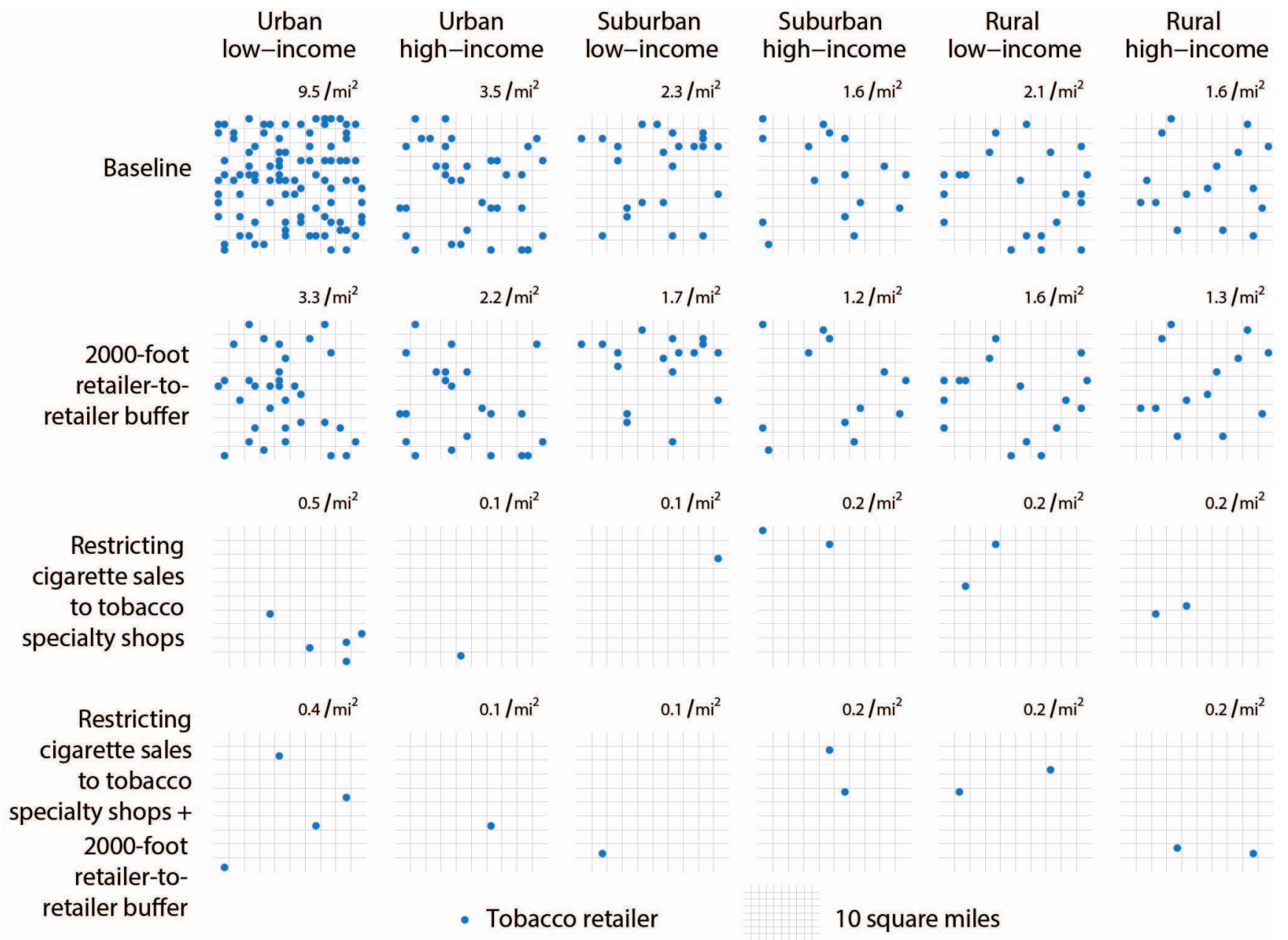

Figure 1 Estimated retailer density reductions, by policy and community.

\section{Use of systems modelling for tobacco control}

Tobacco product availability and purchasing decisions that impact initiation, consumption and cessation are the results of complex, dynamic systems of interrelated actors and influences. Advancements in tobacco control policy research require modelling tools that match the complexity of these systems. ${ }^{17-19}$ Computational modelling can replicate these multifactorial and interwoven systems by testing population interventions and policies. ${ }^{2021}$ Given the ability of computational modelling to assess the interaction of variables that other models cannot, more tobacco control experts are using this strategy for policy research. ${ }^{22-25}$ For example, the tobacco control macrosimulation SimSmoke has been used to project the impact of policies in Brazil, the Netherlands and China. ${ }^{26-28}$

Agent-based modelling (ABM) is a class of computational model designed to represent complex systems of interactions between people and their environment. By simulating physical and social environments within which agents (e.g., individuals) who exist, behave and interact, $\mathrm{ABMs}$ can provide insight into the underlying mechanisms of tobacco-control policies and their effects. ${ }^{24} 2930$ In our previous work, we developed the Tobacco Town model, an ABM designed to analyse the impact of several retailer density tobacco control policies across suburban and urban communities. Results showed variation in the likely impact of policies across contexts. These results indicated that the mechanisms underlying retailer density reduction and tobacco product cost are not necessarily linear and are heavily dependent on existing retailer density and context. ${ }^{25}$

Our model is guided by the premise that making products more difficult to acquire due to increased direct or indirect costs can lead to fewer purchases and decreased use. ${ }^{31}$ The direct cost of cigarettes is the purchase price paid; the indirect costs include (1) the travel costs (time, distance and fuel or transit costs) used to purchase cigarettes and (2) the opportunity cost of time spent not doing other things. Increasing the price of cigarettes is one reliable way to make them harder to buy and has a direct impact on initiation and cessation. ${ }^{32}$ Other strategies-indeed the primary aims of many retail tobacco policies—such as rendering tobacco products harder to find or increasing the search time or travel distance to purchase, can increase the opportunity costs and the hassle incurred by smokers and would-be smokers. As a result, these indirect costs could likely reduce tobacco product use. Here, we explore the potential of retail tobacco policies to raise the overall costs of acquiring cigarettes.

\section{METHODS}

The model we develop here is a refinement of the Tobacco Town ABM described in Luke and colleagues, which models the influence of the retail environment on individual smokers' purchase decisions. ${ }^{25}$ Here, we introduce four features: (1) product differentiation (menthol vs non-menthol cigarettes); (2) variation in agent menthol cigarette preferences; (3) priority population 
By community

\section{0-foot retailer-to-retailer buffer}

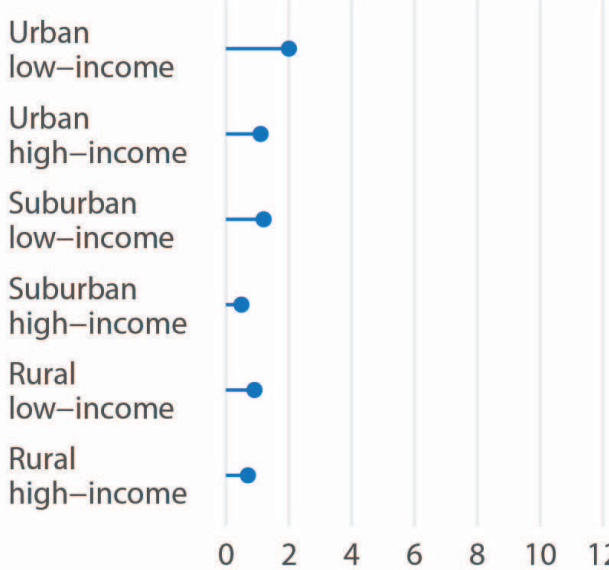

\section{By population}

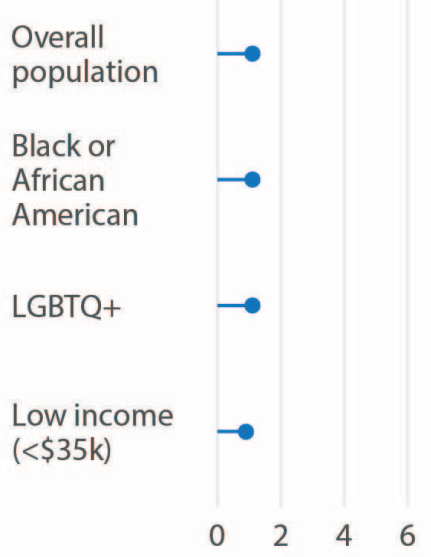

Restricting cigarette sales to tobacco specialty shops

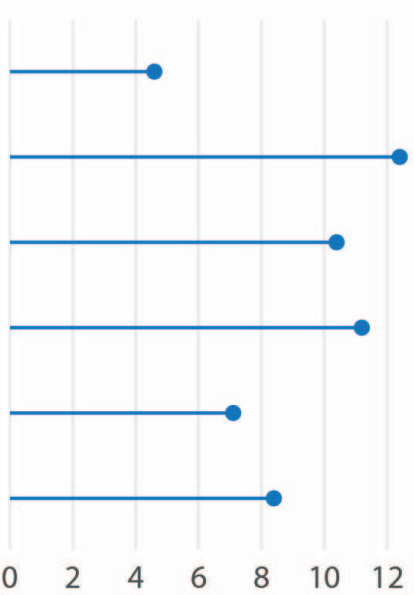

Restricting cigarette sales to tobacco specialty shops 2000 -foot retailer-to-retailer buffer

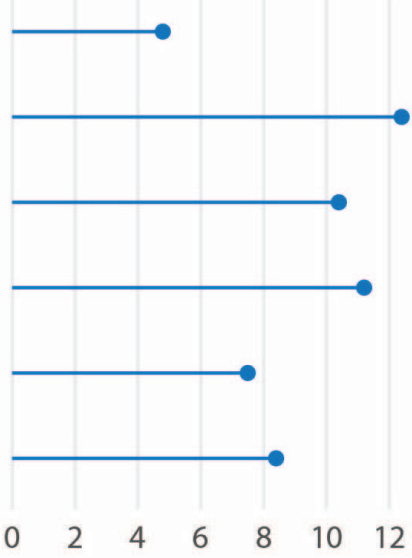

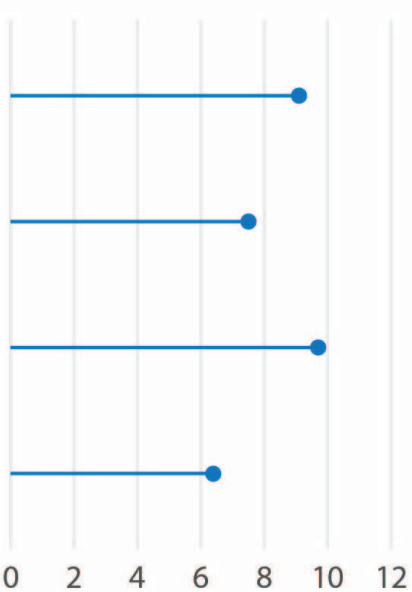

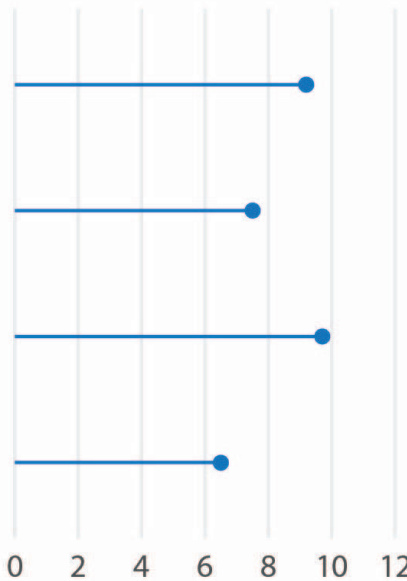

Estimated change (\%) in total costs (direct+ indirect) after policies

representation (African American, low income and lesbian, gay, bisexual, transgender and queer or LGBTQ+ populations) through differentiation of agent characteristics and (4) new input data designed to tailor the model to specific community types in the Minnesota context. A brief description of the model follows (see online supplementary technical appendix for more information on model design and data use).

\section{Agents}

Agents in our model represent adult smokers, each of whom has an array of properties (e.g., income, race, LGBTQ+ status, product preferences, cigarettes consumed per day) that influence their behaviour (see the Dynamics section). ${ }^{33}$ Agent properties are informed by empirical data. For example, menthol cigarette preferences and cigarettes per day come from the pooled results of the 2012 and 2014 versions of the National Adult Tobacco Survey ${ }^{34}$ for each of the eight different types of agents: one high-income and one low-income each for the four possible combinations of (1) Black/African-American or nonBlack/African-American and (2) LGBTQ+ or non-LGBTQ+. Other agent characteristics include mode of transportation from US Census estimates for specific Minnesota Census Designated Places (for rural and suburban communities), price sensitivities (informed by the health economics literature on cigarette price elasticities for smokers of different incomes and races) and home and work locations (generated for each agent based on townlevel properties).

\section{Environment}

Towns are probabilistically generated based, in part, on data from postal (ZIP) codes that represent the typical example for each of the six Minnesota community types. ${ }^{35}$ Location-specific retailer densities, distribution of retailer types (e.g., convenience store or tobacco specialty shop) and cigarette prices for our baseline (i.e., no intervention) condition were provided from surveillance data collected in Minnesota by Counter Tools. ${ }^{36}$

\section{Dynamics}

During each simulated day, agents smoke cigarettes, travel from their home location to work and make purchase decisionswhether, where and which product type to purchase-based on a combination of their own properties (e.g., locations, product preferences, current cigarette inventories and price sensitivities) and the retail environment (i.e., retailer locations and price offerings). Purchase decisions are made using both direct and indirect costs; the latter (travel and opportunity costs) are calculated according to each agent's wages and mode of transportation. 


\section{Model use}

At baseline, we observe the behaviour of agents over the course of three simulated months. We collect data on the average daily costs incurred by agents, as well as patterns in purchase behaviour. For each community type, we run each policy simulation 50 times to gauge the variation in outcomes due to stochasticity. We record the behaviour of the model at baseline, then simulate the implementation of various policies and policy combinations. We characterise the potential impact of each policy scenario by comparing averages of model outcomes before and after policy implementation. While we do not present results from all the policy experiments modelled, all are available at https:// tobaccotown.shinyapps.io/Minnesota/ The five policy scenarios presented here are:

1. Prohibiting retailers from being located within 2000 feet of another, that is, 2000-foot retailer-to-retailer proximity buffer.

2. Restricting menthol cigarette sales to tobacco specialty shops.

3. Restricting menthol cigarette sales to tobacco specialty shops in combination with a 2000-foot retailer-to-retailer proximity buffer.

4. Restricting all cigarette sales to tobacco specialty shops.

5. Restricting all cigarette sales to tobacco specialty shops in combination with a 2000-foot retailer-to-retailer proximity buffer.

\section{RESULTS}

Here, we present the results of the policy scenarios that show the strongest potential influence and equitable effects on three key outcomes including retailer density reduction, changes in total (direct and indirect) costs per cigarette pack and changes to the average distance travelled to purchase.

\section{Outcome: retailer density}

We characterise the potential impact of retailer density reduction policies on retailer density in figure 1 . The top row represents density at baseline for each community type and the other policy conditions are ordered from smallest (row 2) to largest impact (bottom). The densities in stores per square mile are above each grid. From left to right are the various community types. Each individual plot characterises the density of tobacco retailers in a $10 \mathrm{~m}^{2}$ grid. Each dot represents one retailer. The single policy with the largest modelled impact on density reduction was restricting all cigarette sales to tobacco specialty shops, especially in urban low-income areas, reducing retailer density from approximately 10 retailers $/$ mile $^{2}<1$ retailer $/$ mile $^{2}$. Combining the restriction of sales to tobacco specialty shops with the 2000foot retailer-to-retailer buffer did not show notable benefits over the store type restriction as an individual policy.

\section{Outcome: total costs}

We also examined the probable impact of policies on the total direct and indirect costs for consumers per pack, shown in figure 2. The top row of plots shows the results by community, and the bottom row shows the results by population of interest. Within each plot cell, each line-dot represents the estimated percentage increase in the total costs per pack after introduction of the specific policy. For all community types, the proximity buffer alone shows minor probable effects. The sales restriction to tobacco specialty shops shows a potential increase of at least 5\% across communities. However, all other communities see markedly larger increases compared with urban low-income environments, where retailer density is disproportionately high (figure 1). Also, the projected percentage increase in total costs for each of the low-income areas is less than that for its higher income counterpart, with the smallest difference being between suburban low-income and high-income communities $(<1 \%)$. The largest increases shown are for urban $(>12 \%)$ and suburban $(>11 \%)$ high-income communities, where lower proportions of smokers reside. Adding the buffer to the sales restriction shows minor immediate additional effects of 0 to $0.4 \%$ in each case.

In the bottom row of figure 2 , we see the projected impacts of policy implementation on total costs for the three priority populations, Black or African American, LGBTQ+ and low income. Effects are similar to those for the general population, with minor increases for the buffer alone and estimated cost increases from just over $6 \%$ to $10 \%$ for the store type sales restriction alone or when paired with the buffer. The highest potential increases are seen for LGBTQ+ individuals and low-income and Black or African American individuals.

We isolated changes in the total costs for menthol cigarettes and also looked at the potential impact on total (direct and indirect) costs of menthol cigarettes by limiting the sale of menthol cigarettes to tobacco specialty shops when paired with a 2000 -foot retailer-to-retailer proximity buffer. Figure 3 shows the estimated percentage increase in total costs per pack of menthol cigarettes. Agents, according to their menthol preference (smoking menthol never, sometimes, mostly, or always) as informed by the National Adult Tobacco Survey data, ${ }^{34}$ may choose to purchase menthol or non-menthol after policy implementation. As in figure 2, results are presented separately by community (top) and population (bottom). Restricting menthol sales to tobacco specialty shops alone projected at least a $7 \%$ increase in the total cost of menthol for all communities, except for urban low-income areas, where menthol cost increases were just over 3\%. The largest increase was estimated for suburban low-income communities at just over 13\%. Next, when adding the 2000-foot retailer-to-retailer proximity buffer to the restriction limiting the sale of menthol cigarettes to tobacco specialty shops, the percentage change in cost increases is higher for each community type. While there still are inequities in terms of the effect of this policy, there is a more than twofold increase in the projected change in total indirect and direct costs in urban, lowincome communities (from around 3\% to $8 \%$ ).

In the bottom row of figure 3 , we see that restricting the sale of menthol cigarettes to tobacco specialty shops results in estimates of at least a $6 \%$ increase in all populations. Pairing this policy with the buffer sees at least a 7\% estimated increase. The lowest potential increases are seen for low-income and African American populations.

\section{Outcome: distance travelled to purchase}

The policies tested operate to increase the indirect costs (i.e., time, distance, travel) of purchasing cigarettes. Figure 4 shows the potential increases in the average distance travelled to purchase cigarettes by community (top) and population (bottom). The vertical lines at the left end of each segment represent the average distance travelled at baseline, and the arrows at the right end of each segment point to the average distance after policy implementation. We show these in miles rather than relative percentages to show the inequities of average distance travelled at baseline and the equity-increasing potential of each policy.

At baseline, the average distance to purchase is lowest in urban low-income communities and for Black or African Americans, and is highest in rural communities and for low-income smokers. The average distance for all communities when restricting 

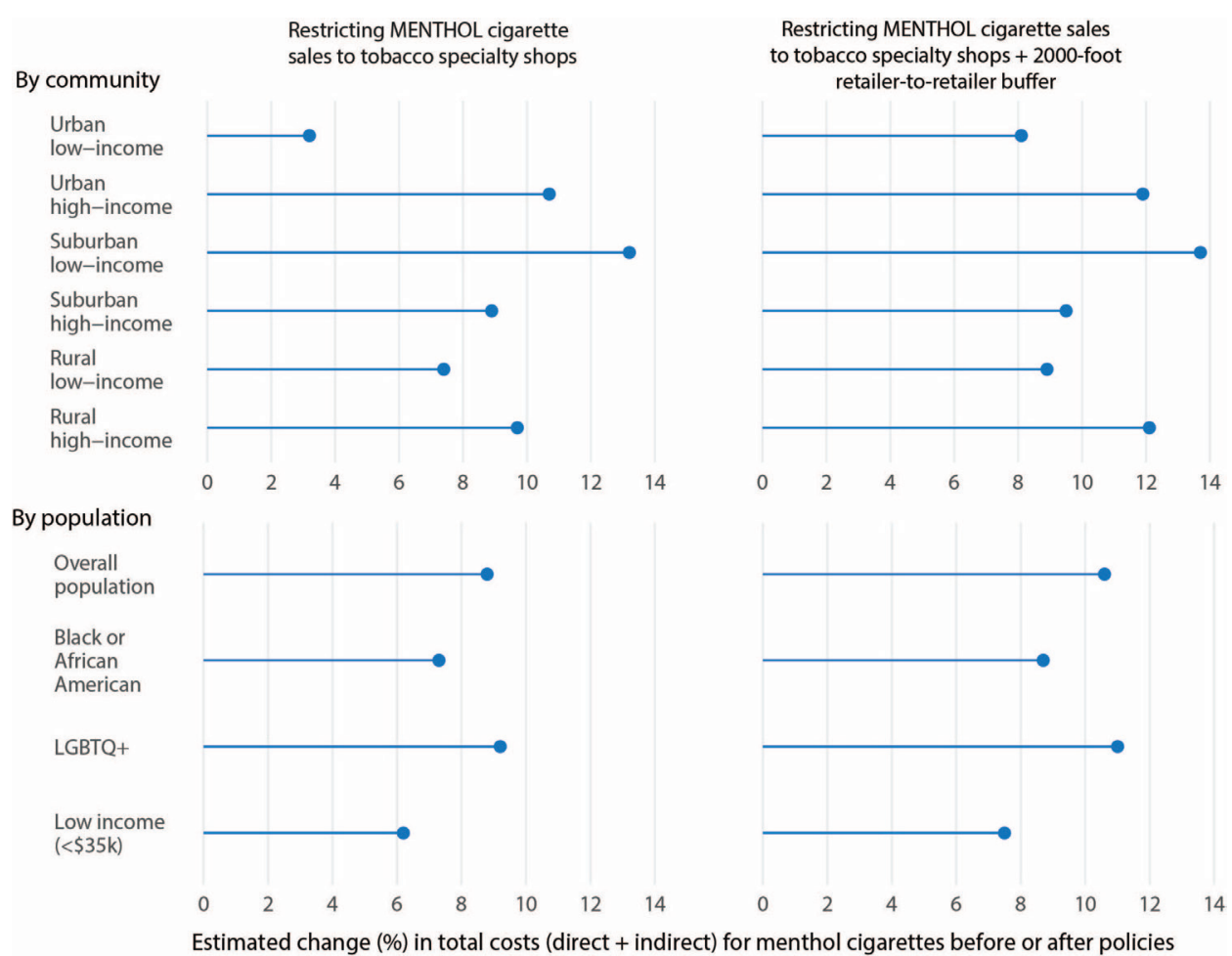

Figure 3 Estimated percentage cost increases per pack for menthol cigarettes after menthol sales restriction alone and paired with a 2000-foot retailer proximity buffer.

cigarette sales to specialty shops is at or just over two miles, except for urban low-income communities, in which average distance remains the lowest at around one mile. The same trends are seen when focusing on priority populations, where average estimated distances are about 2 miles after restricting sales to specialty shops.
Figure 5 shows the potential changes in distance to purchase menthol cigarettes, by community (top) or population (bottom). We see that the sales restriction for menthol cigarettes estimates average distances of over 2 miles for all communities, except lowincome urban ones. However, when paired with the 2000-foot retailer buffer, the average estimated distance for all community
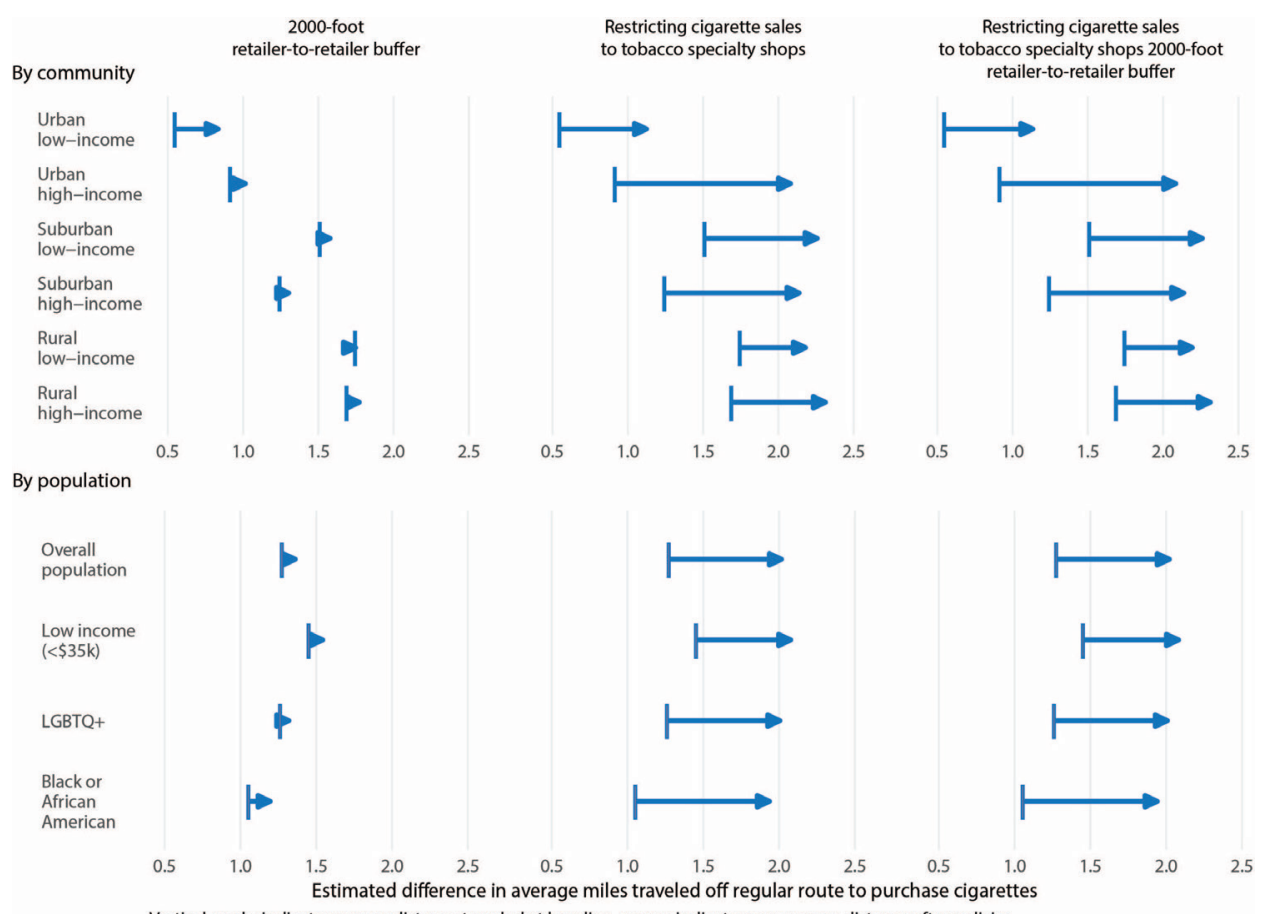

Figure 4 Estimated changes in the average distance travelled to purchase cigarettes after policies. 


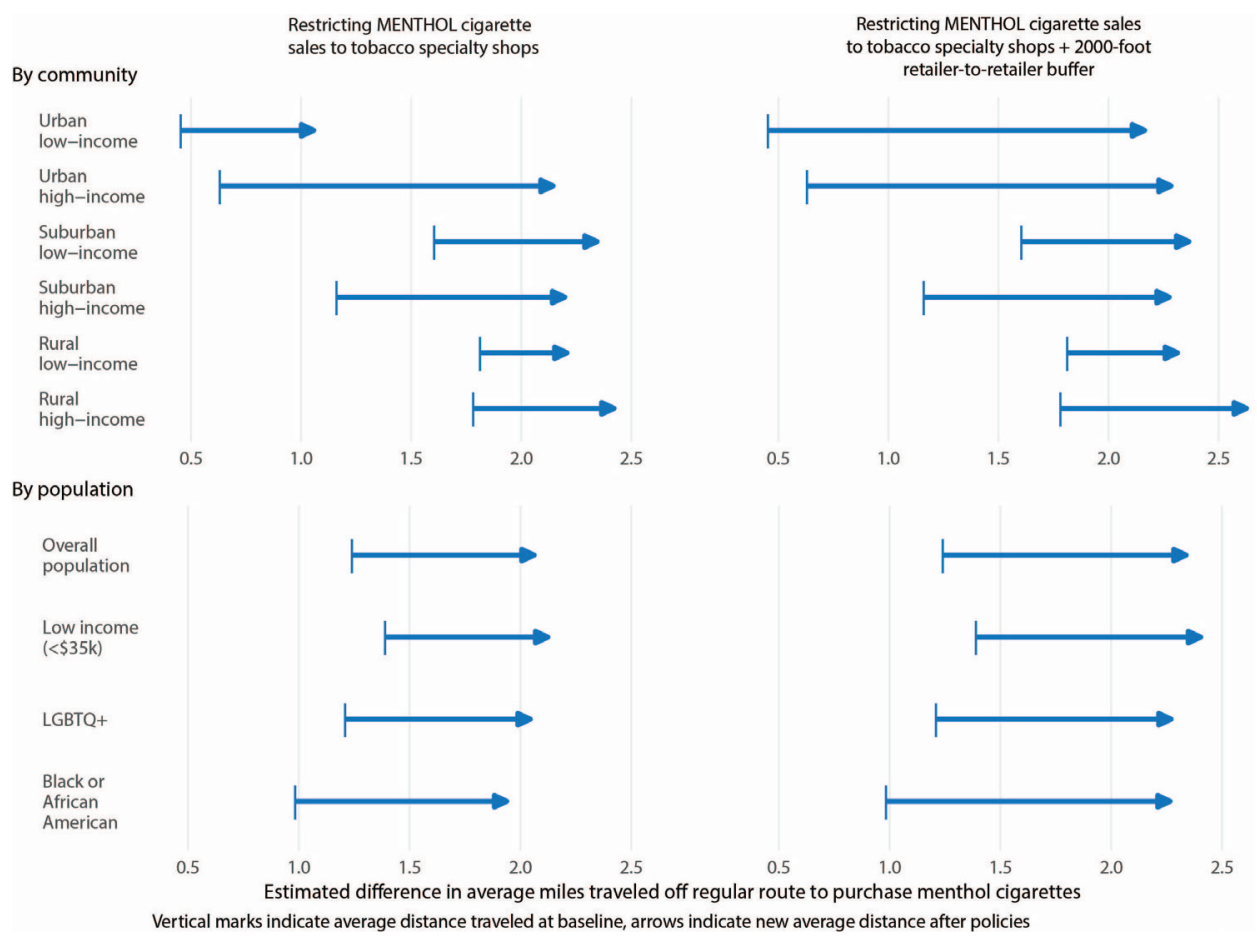

Figure 5 Estimated changes in the average distance travelled to purchase menthol cigarettes after policies.

types is 2 or more miles and more equal across communities. For priority populations, the average distance after the sales restriction alone is near or above two miles, and the estimates increase and are slightly more equal with the addition of the buffer policy.

\section{DISCUSSION}

In this paper, we present results of policy implementation simulations that support the potential of community-based retail policies for reducing tobacco consumption and promoting health equity. Computational modelling strategies-particularly $\mathrm{ABM}$ - are well-suited to perform experiments about the potential impact of policies, especially for relatively new approaches without a sufficient evidence base. Our model uses real-world input data from six typical Minnesota communities to test the potential impact of various menthol cigarette sales restrictions, retailer density reduction policies and their combinations. The twin goals of these and most retail-focused strategies are to reduce smoking by (1) reducing the availability of products and (2) making it more difficult to acquire tobacco products.

The importance of context, here the urbanicity and wealth of communities, is evident in our results presented for all policies. Low-income communities in Minnesota and beyond, especially urban ones, experience disproportionately high tobacco retailer density. As a result, the impact of policies may be generally smaller in these communities than in higher income ones. This requires stakeholders and policymakers to tailor or combine policies as appropriate given the setting (sometimes referred to as 'precision' prevention) $)^{32}$ to get the most impact from their policy efforts and help to prevent exacerbating current disparities in density, especially in low-income urban areas.

Communities often implement policies to reduce health disparities among priority populations. Our results suggest that retail policies aimed at increasing direct and indirect costs of purchasing cigarettes and, presumably, reducing smoking among low-income or Black or African-American populations might impact them less than for the overall population. This is likely because they live in retailer-dense areas (Black or African-American smokers) or travel farther on average (lower income smokers) to purchase cheaper products. In almost all the individual policy simulations, low-income smokers were least impacted, and Black or AfricanAmericans were the next lowest affected population. However, the combination of policies, especially combining a restriction of menthol or all cigarette sales to tobacco specialty shops and a 2000-foot retailer-to-retailer buffer, may equalise the average distance necessary to travel to purchase for low-income, Black or African-American, and LGBTQ+ populations with those of the overall population. These specific findings and similar ones found in the online dashboard could help to draw in communitybased and population-based advocacy groups (e.g., LGBTQ+, racial justice, low-income housing groups) that may not be traditional tobacco control partners. Restricting all cigarette sales to tobacco specialty shops, with or without the buffer, may increase the necessary distance to more equal levels. While the addition of the buffer policy to the store-type sales restriction may not show large immediate effects on total costs, another possible benefit of combining the two policies is to guard against counterproductive industry or retailer reactions to policy implementation. Possible actions after restricting menthol sales to tobacco specialty shops, such as opening new tobacco specialty shops or creating 'stores within stores' (i.e., enclosed or otherwise restricted access sections in existing non-specialty retailers that qualify as tobacco shops). Having a buffer policy in place is one way to forestall such actions.

The feasibility of adopting different retail policies will vary by community due to a number of different factors, such as political support and community readiness, the existing policy landscape, the scope of local authority, the availability of information about the location and types of local retailers, enforcement mechanisms and capabilities and coalition expertise. For example, in the absence of educational campaigns about the tobacco retail environment and the evidence supporting policy interventions, school-buffer policies initially may be more appealing to 
decision-makers than retailer-to-retailer buffer zones or menthol sales restrictions. Or, in communities without retailer licensing data or the capability to show the location of retailers on maps, pharmacy sales restrictions initially may be more appealing to decision-makers than other policy options.

The model presented here has several limitations that we hope to address in future work. First, it assumes that agents live, work and purchase tobacco within a single community; there are no spillover effects, where agents living in an area affected by policy simply travel to purchase in the neighbouring community or online. Because a substantial share of routine purchases are likely made within $10 \mathrm{~min}$ distance from home, ${ }^{37}$ we feel this is a justifiable assumption, but policymakers should bear in mind such spillover effects when crafting tobacco retail policies. Second, the tobacco retailers themselves do not adapt their prices or other behaviours in response to policy, as we might expect in real-world settings. Third, our model accounts only for cigarettes and not other tobacco products. Finally, a limitation that some may cite is our focus on only Minnesota communities. However, the relative impacts, for example, percentage increases in total costs or distance travelled to purchase, would translate well to other communities in other states and countries that have similar types of geographic and population-based tobacco use disparities. Since we include a large range of tobacco retailer densities and the underlying mechanism-smokers' decisions of where to buy and how much to spend-is likely similar for most or all smokers.

In other fields, $\mathrm{ABM}$ and similar computational models play an important role in informing design of policies that are more effective, sustainable or robust to uncertainty. ${ }^{33}$ This reflects the ability of computational models to complement more conventional tools (such as randomised controlled trials and empirical analyses of observational data) by considering larger and more heterogeneous populations, more accurate spatial patterns and more policy combinations over longer time horizons. The

\section{What this paper adds}

\section{What is already known on this subject}

- Retail-focused tobacco control policies, other than youth access restrictions or retailer licensing laws, are relatively new. Their impact is not as well documented compared with other policy domains such as excise tax or smoke-free air. However, we do know that higher retailer density is associated with greater tobacco use and reduced cessation, and that retailer density reduction policies actually reduce density.

What important gaps in knowledge exist on this topic

- Despite the recent growing popularity of retail-focused tobacco control policy, knowledge gaps persist regarding (1) the effectiveness of specific policies and policy combinations and (2) the relative impact of different policy scenarios over time on retailer density and smoking rates. Equity considerations are also underexplored.

\section{What this paper adds}

- Our research offers estimates of the potential impact of various menthol cigarette sales restrictions and retailer density reduction policies on tobacco retailer density and the overall costs of purchasing cigarettes in six different community types among the general population and for three priority populations. potential for similar uses in public health, particularly chronic disease prevention, has been clear for several years, but applied examples have been relatively sparse. The results presented here show how a general model such as Tobacco Town can be successfully applied to a specific context and set of policy questions to yield actionable insights. We hope that other such efforts will follow in coming years.

Acknowledgements The authors thank ClearWay MinnesotaSM for funding this study, Grant Number RC-2017-0010, as part of its goal to reduce health tobaccorelated health disparities.

Contributors TBC led data collection for input data, analyses of model results and paper development and writing. VRM worked on analyses of model results and paper development, organisation and writing.JO, MK and BH participated in model development and execution and in paper writing. MM and KC participated in data collection for input data and paper writing. DB aided data collection for input data, analyses of model results and paper writing. RAH led model development and participated in model execution and paper writing. DL oversaw data analyses and participated in paper writing.

Funding This study was funded by ClearWay Minnesota (Grant number: RC-20170010).

Competing interests None declared.

Patient consent for publication Not required.

Provenance and peer review Not commissioned; externally peer reviewed.

Data availability statement Data may be obtained from a third party and are not publicly available.

Open access This is an open access article distributed in accordance with the Creative Commons Attribution Non Commercial (CC BY-NC 4.0) license, which permits others to distribute, remix, adapt, build upon this work non-commercially, and license their derivative works on different terms, provided the original work is properly cited, appropriate credit is given, any changes made indicated, and the use is non-commercial. See: http://creativecommons.org/licenses/by-nc/4.0/.

\section{ORCID iD}

Todd B Combs http://orcid.org/0000-0003-1015-6589

\section{REFERENCES}

1 United States Surgeon General. The health consequences of smoking - 50 years of progress: a report of the surgeon general: (510072014-001. Atlanta (GA): Centers for Disease Control and Prevention (US), 2014.

2 Leas EC, Schleicher NC, Prochaska JJ, et al. Place-Based inequity in smoking prevalence in the largest cities in the United States. JAMA Intern Med 2019. doi:10.1001/jamainternmed.2018.5990. [Epub ahead of print: 07 Jan 2019].

3 WHO Study Group on Tobacco Product Regulation. Banning menthol in tobacco products: Advisory note. WHO. Available: http://apps.who.int/iris/bitstream/handle/ 10665/205928/9789241510332_eng.pdf;jsessionid=E7F6AF71E5FDE10B06E33133 A7CCAE19? sequence $=1$ [Accessed 9 Dec 2018].

4 Revision of the Tobacco Products Directive - Public Health - European Commission. Public health. Available: /health/tobacco/products/revision_en [Accessed 9 Dec 2018].

5 Government of Canada PW and GSC. Canada Gazette - order amending the schedule to the tobacco act (menthol). Available: http://www.gazette.gc.ca/rp-pr/p1/2016/ 2016-11-05/html/reg5-eng.html [Accessed 9 Dec 2018].

6 Government of Canada PW and GSC. Canada Gazette - order amending the schedule to the tobacco act (menthol). Available: http://www.gazette.gc.ca/rp-pr/p2/2017/ 2017-04-05/html/sor-dors45-eng.html [Accessed 9 Dec 2018].

7 Public Health Law Center. Leading from up North: how Canada is solving the menthol tobacco problem. Available: https://www.publichealthlawcenter.org/sites/default/files/ resources/tclc-Canadian-Menthol-CaseStudy-2017.pdf [Accessed 9 Dec 2018].

8 Public Health Law Center. How other countries regulate flavored tobacco products, 2016. Available: https://www.publichealthlawcenter.org/sites/default/files/resources/ tclc-fs-global-flavored-regs-2015.pdf [Accessed 9 Dec 2018].

9 US Food \& Drug Administration. Preliminary scientific evaluation of the possible public health effects of menthol versus Nonmenthol cigarettes, 2013: 153.

10 Villanti AC, Collins LK, Niaura RS, et al. Menthol cigarettes and the public health standard: a systematic review. BMC Public Health 2017;17:983.

11 San Francisco Board of Supervisors. Ordinance amending the health code to Prohibit tobacco Retailers from Selling flavored tobacco products, including menthol cigarettes, 2017. Available: https://sfgov.legistar.com/View.ashx?M=F\&ID=5303550\& GUID=8D715199-F0C9-48F1-9752-D7E66F16C90C [Accessed 9 Dec 2018].

12 Public Health Law Center. Us sales restrictions flavored tobacco products, 2018. Available: https://www.publichealthlawcenter.org/sites/default/files/resources/US Sales-Restrictions-Flavored-Tobacco-Products-2018.pdf [Accessed 9 Dec 2018] 
13 Ackerman A, Etow A, Bartel S, et al. Reducing the density and number of tobacco retailers: policy solutions and legal issues. NICTOB 2017;19:133-40.

14 Riches E, Whitehead R, Rennick L. What is the causal link between tobacco outlet density and smoking prevalence? Edinburgh: NHS Scotland, 2018.

15 Luke DA, Sorg AA, Combs T, et al. Tobacco retail policy landscape: a longitudinal survey of US states. Tob Control 2016;25(Suppl 1):i44-51.

16 Center for Public Health Systems Science, Brown School, Washington University in St. Louis. Point-of-sale report to the nation: realizing the power of states and communities to change the tobacco retail and policy landscape. St. Louis, MO: Washington University in St. Louis, 2018.

17 Mabry PL, Olster DH, Morgan GD, et al. Interdisciplinarity and systems science to improve population health: a view from the NIH office of behavioral and social sciences research. Am J Prev Med 2008;35(2 Suppl):S211-24.

18 Van Wave TW, Scutchfield FD, Honoré PA. Recent advances in public health systems research in the United States. Annu Rev Public Health 2010;31:283-95.

19 Committee on the Assessment of Agent-Based Models to Inform Tobacco Product Regulation, Board on Population Health and Public Health Practice, Institute of Medicine. Geller A, Ogawa VA, eds. Assessing the use of agent-based models for tobacco regulation. Washington (DC: National Academies Press (US), 2015.

20 Hammond RA. Complex systems modeling for obesity research. Prev Chronic Dis 2009;6:A97.

21 Homer JB, Hirsch GB. System dynamics modeling for public health: background and opportunities. Am J Public Health 2006;96:452-8.

22 Levy DT, Bauer JE, Lee H-R. Simulation modeling and tobacco control: creating more robust public health policies. Am J Public Health 2006;96:494-8.

23 Mendez D, Warner KE. Smoking prevalence in 2010: why the healthy people goal is unattainable. Am J Public Health 2000;90:401-3.

24 Pearson AL, Cleghorn CL, van der Deen FS, et al. Tobacco retail outlet restrictions: health and cost impacts from multistate life-table modelling in a national population. Tob Control 2017;26:579-85
25 Luke DA, Hammond RA, Combs T, et al. Tobacco town: computational modeling of policy options to reduce tobacco Retailer density. Am J Public Health 2017; 107:740-6.

26 Nagelhout GE, Levy DT, Blackman K, et al. The effect of tobacco control policies on smoking prevalence and smoking-attributable deaths. findings from the Netherlands SimSmoke tobacco control policy simulation model. Addiction 2012;107:407-16.

27 Levy D, Rodríguez-Buño RL, Hu T-W, et al. The potential effects of tobacco control in China: projections from the China SimSmoke simulation model. BMJ 2014;348:g1134.

28 Levy D, de Almeida LM, Szklo A. The Brazil SimSmoke policy simulation model: the effect of strong tobacco control policies on smoking prevalence and smokingattributable deaths in a middle income nation. PLoS Med 2012;9:e1001336.

29 Luke DA, Stamatakis KA. Systems science methods in public health: dynamics, networks, and agents. Annu Rev Public Health 2012;33:357-76.

30 Borshchev A, Filippov A. From system dynamics and discrete event to practical agent based modeling: reasons, techniques, tools, 2004: 23.

31 Solek A. Behavioral economics approaches to public policy. JOIS 2014;7:33-45.

32 Chaloupka FJ, Cummings KM, Morley CP, et al. Tax, price and cigarette smoking: evidence from the tobacco documents and implications for tobacco company marketing strategies. Tob Control 2002;11(Suppl 1):i62-72.

33 Hammond RA. Considerations and best practices in agent-based modeling to inform policy. In: Assessing the use of Agent-Based models for tobacco regulation. Washington, DC: The National Academies Press, 2015.

$34 \mathrm{CDC} \mathrm{O}$ on $\mathrm{S}$ and $\mathrm{H}$. Smoking and tobacco use; data and statistics; national adult tobacco survey (NATS). smoking and tobacco use. Available: http://www.cdc.gov/ tobacco/data_statistics/surveys/nats/ [Accessed 13 Dec 2018].

35 Gillman MW, Hammond RA. Precision treatment and precision prevention: integrating "below and above the skin". JAMA Pediatr 2016;170:9-10.

36 Counter Tools. Welcome! | store audit center. Available: https://assess.countertools. org/ [Accessed 16 Jan 2019].

37 Access Development. Access consumer spend study: the impact of retail proximity on consumer purchases. Available: https://cdn2.hubspot.net/hubfs/263750/Access_ Consumer_Spend_Study_2016.pdf [Accessed 13 Jun 2019]. 